\title{
The alternative spinal recovery position
}

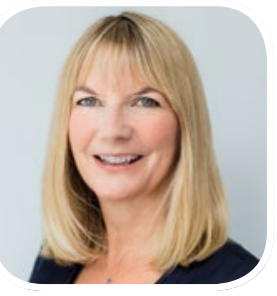

Emma

Hammett, CEO of First

Aid for Life, describes

\section{a recovery position}

for a casualty who is

suspected of having a

spinal injury.

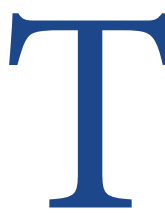

he General Dental Council's (GDC's) document Scope of practice $(2013)^{1}$ states: 'A patient could collapse on any premises at any time, whether

they have received treatment or not. It is therefore essential that ALL registrants are trained in dealing with medical emergencies, including resuscitation, and possess up to date evidence of capability'. The standards for managing a medical emergency are set by The Resuscitation Council (UK). ${ }^{2}$
Consequently, all dental professionals should undertake annual mandatory training covering emergency life support and first aid for dental emergencies. On these first aid courses you may be taught some different options for the recovery position. Often, in addition to the standard recovery position, your trainer may explain adaptations and the log roll for an unconscious but breathing casualty who is suspected of having a spinal injury. The idea of these alternative approaches is to minimise any twist to the casualty's spine whilst rolling them into a position to protect their airway.

\section{When is the recovery position} advised?

The recovery position is indicated when a casualty is unconscious and breathing normally. It is a sensible way of positioning someone to allow the tongue to flop forward and any fluids to drain out, reducing the risk of them entering the airway (Fig. 1).

When someone is unresponsive and lying

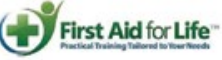
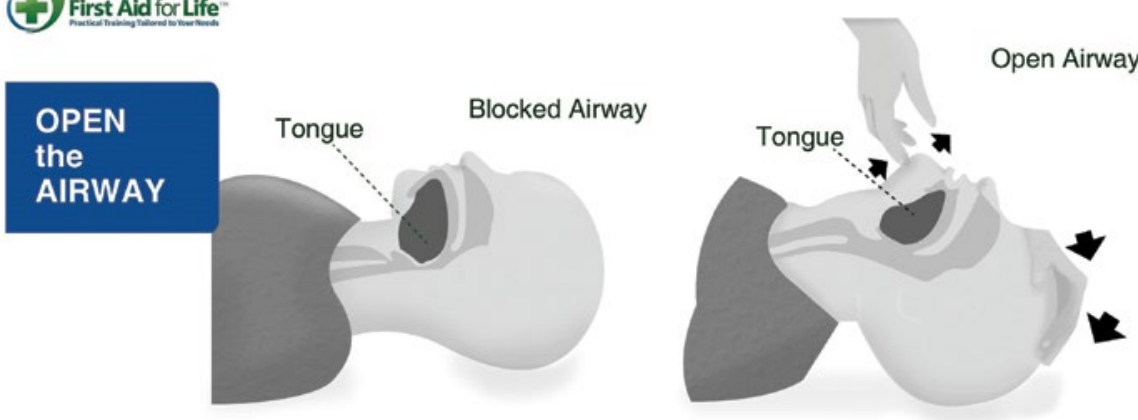

Fig. 1 First Aid for Life Open the Airway diagram 


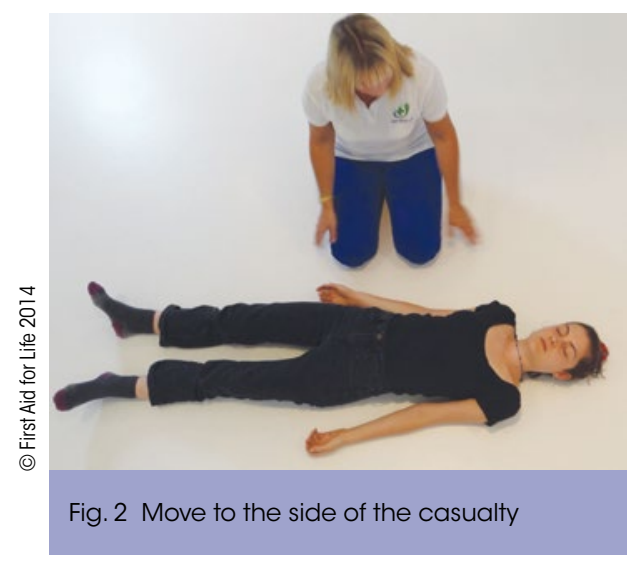

Spinal injuries

NICE estimate that approximately 700 people sustain a new spinal cord injury (SCI) each year in the UK. In the UK there are currently 40,000 people living with long term disabilities as a result of such injuries.

Helping the casualty to maintain a clear airway is critical and takes priority over any suspected spinal injury, as if their airway is blocked, they are unable to breathe. To maintain an open airway anyone who is unconscious and breathing should ideally be rolled onto their side into the recovery position.

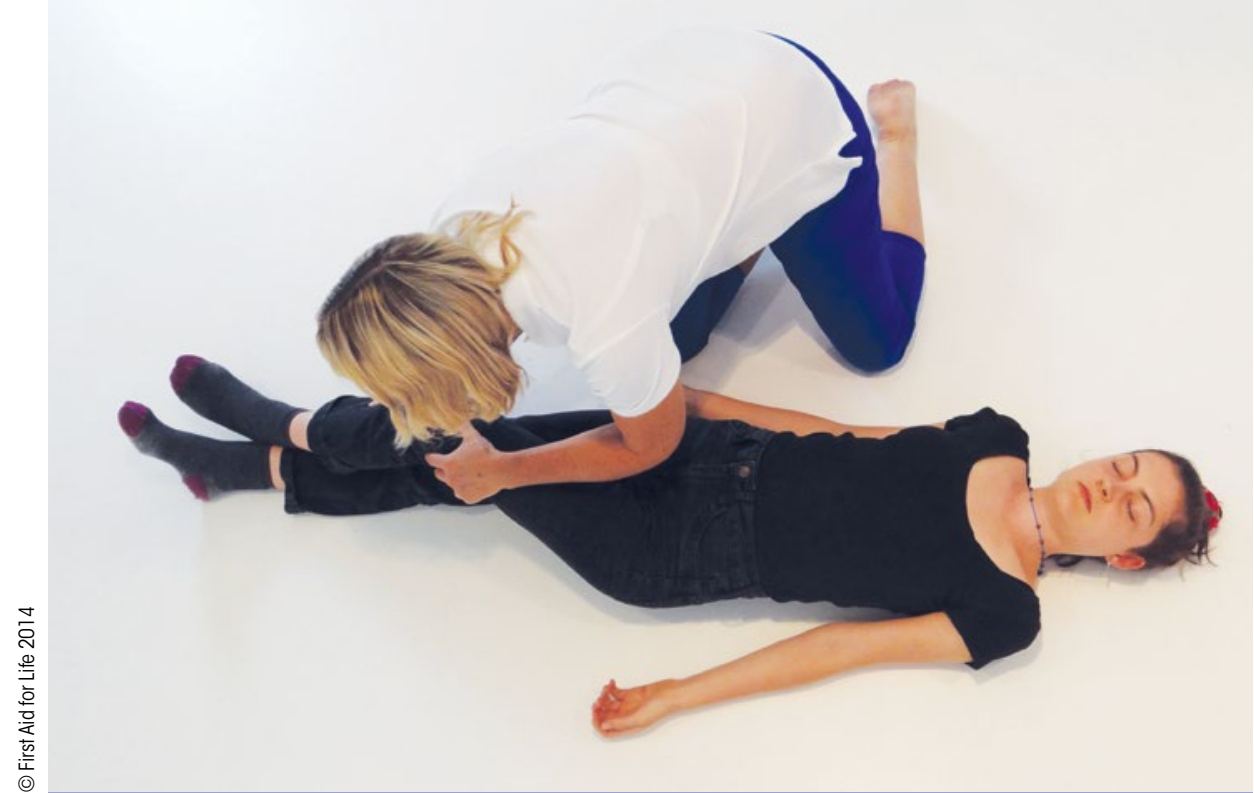

Fig. 3 Cross the casualty's legs, bringing the far leg towards you

\section{'Dental professionals should be ready}

\section{to suction if there are signs}

\section{of aspiration. Putting someone on their}

\section{side in the recovery position can}

\section{help maintain a clear airway.'}

on their back, gravity can result in the back of their tongue flopping backwards and blocking their airway. In addition, secretions or vomit can lead to aspiration. Dental professionals should be ready to provide suction if there are signs of aspiration. Putting someone on their side in the recovery position can help maintain a clear airway.

If the casualty stops breathing normally at any time, or demonstrates agonal breathing, you should start CPR.
However, spinal injuries can be unstable, and it is vital that in moving the casualty, you don't cause further damage to the spinal cord. If there are multiple people able to assist, then supporting the head and neck, and log rolling the casualty is the best approach to minimise movement to their spine.

However, we haven't always got the luxury of numerous helpful assistants. Therefore, Professor Keith Porter ${ }^{3}$ has developed a further option that makes it easier for one person to roll someone into the recovery position with minimal movement of their spine.

It is incredibly important to keep the spine in line and avoid them twisting. It is vital to keep checking the casualty is breathing.

The benefits of this alternative method ${ }^{4}$ to roll someone into the recovery position are:

1. It reduces the risk of movement to spine and inducing paralysis

2. It is easier for a solo first aider to perform.

Step by step guide to this approach for the first aider

1. Move to the side of the casualty (Fig. 2)

2. Cross the casualty's legs, bringing the far leg towards you (Fig. 3)

3. Carefully slide the casualty's nearest arm under their head with their palm facing upwards (Fig. 4). Remember to do this with minimal movement of the casualty's head. This is best done by using one hand to support their neck whilst sliding their other hand under their head. Slide until the casualty's head rests on top of their palm (Fig. 5)

4. Bring the casualty's other arm across their chest and towards you (Fig. 6)

5. Grasp their far shoulder and their hip simultaneously (Fig. 7)

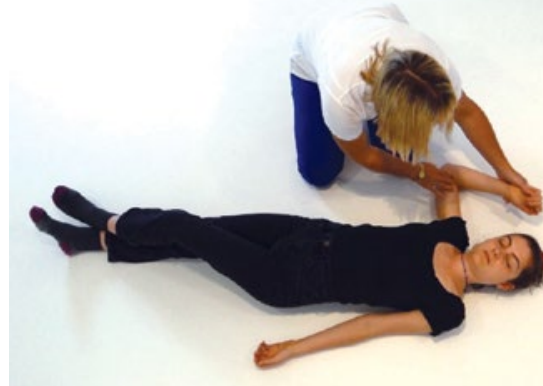

Fig. 4 Carefully slide the casualty's nearest arm under their head with their palm facing upwards

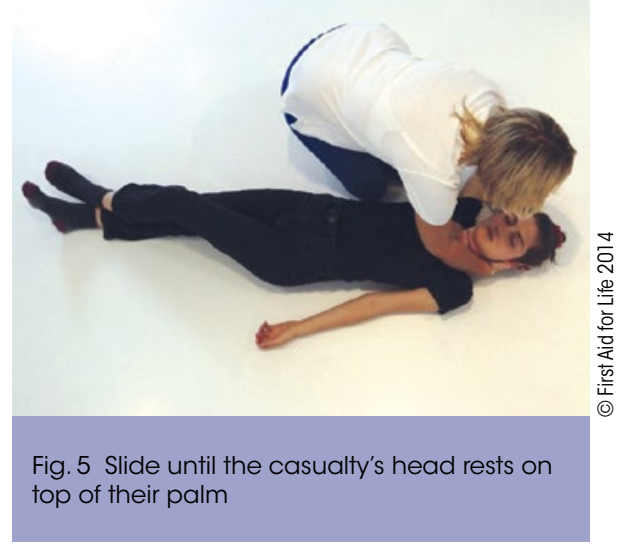




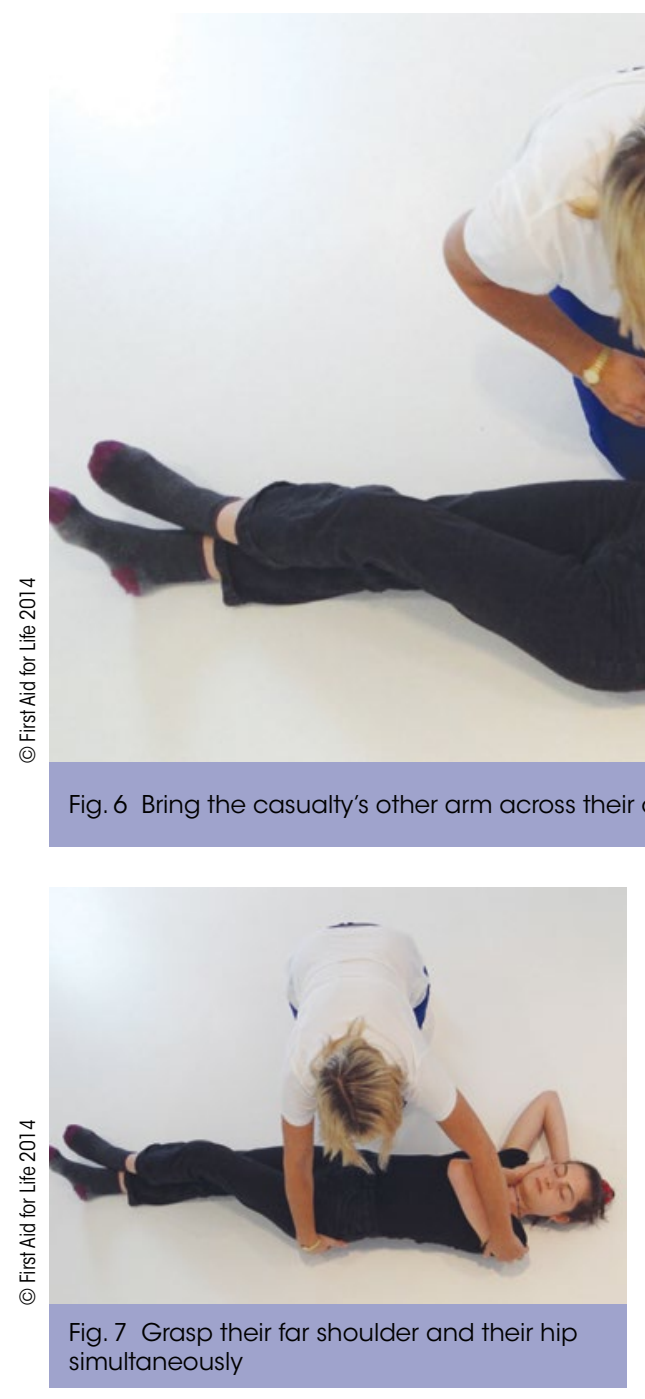

First Aid for Life

First Aid for Life teach the recovery position on all of its practical and online courses.

It is strongly advised that you attend a fully regulated practical or online first aid course to understand what to do in a medical emergency. Visit https://firstaidforlife.org.uk or call 020 86754036 for more information about First Aid for Life's courses.

First Aid for Life is a multi-award-winning, fully regulated first aid training provider specialising in first aid and medical emergency

\section{'If there are multiple people able to}

\section{assist, then supporting the head}

\section{and neck, and log rolling the casualty}

\section{is the best approach to minimise}

\section{movement to their spine.'}

6. Pull equally on each to roll the casualty towards you so that they are resting on their side (Fig. 8)

7. Adjust the upper leg so that the hip and knee are at a right angle (Fig. 9)

8. Continually monitor breathing until help arrives - this is absolutely vital (Fig. 10).

First Aid for Life have produced a video showing this alternative method and it can be viewed at https://firstaidforlife.org.uk/spinalrecovery-position/. training for dental practices. Specific online first aid courses for dental professionals are available at www.onlinefirstaid.com and include six hours of CPD.

First Aid for life provides this information for guidance and it is not in any way a substitute for medical advice. First Aid for Life is not responsible or liable for any diagnosis made, or actions taken based on this information.

\section{References}

1. General Dental Council. Scope of practice. Updated 28 June 2019. Available at: https://

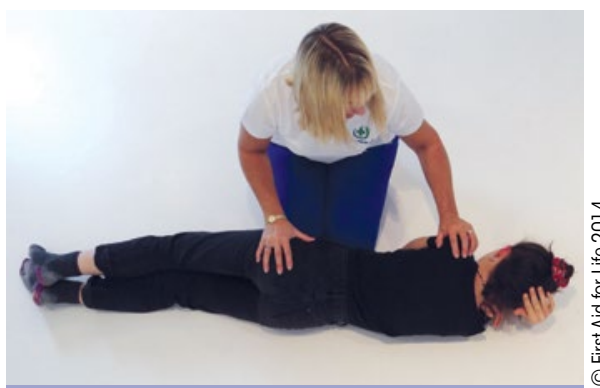

Fig. 8 Pull equally on the casualty's far shoulder and their hip to roll them towards you so that they are resting on their side
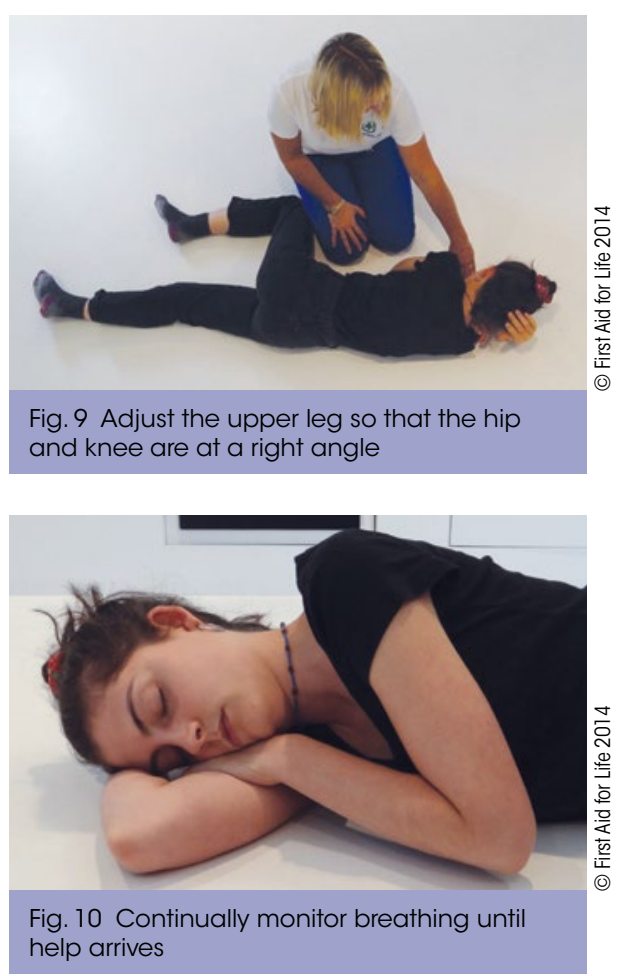

www.gdc-uk.org/information-standardsguidance/standards-and-guidance/scope-ofpractice (accessed 3 March 2020).

2. Resuscitation Council (UK). Quality standards for cardiopulmonary resuscitation practice and training. Updated May 2017. Available at: https://www.resus.org.uk/ quality-standards/primary-dental-carequality-standards-for-cpr/ (accessed 3 March 2020).

3. Hussain N, Dobbie A, Allison K P, England M, Porter K M. A modified recovery position. J R Army Med Corps 2004; 150: 81-83. Available at: https://firstaidforlife.org. uk/wp-content/uploads/2020/02/Spinalrecovery-position-paper-prof-keith-porter_ compressed.pdf (accessed 3 March 2020).

4. Qualsafe.com. New Spinal Recovery Position. June 2019. Available at: https:// firstaidforlife.org.uk/wp-content/ uploads/2020/02/Qualsafe-Spinal-RecoveryPosition-Evidence-Base_compressed.pdf (accessed 3 March 2020). https://doi.org/10.1038/s41407-020-0259-3 